reminded me of my own experience in 1951 after I had qualified BDS LDS at Manchester and applied to British Columbia for admission to their dental register. After some lengthy correspondence my Manchester degree was accepted but I was informed that I would have to complete two years of 'pre-dental' study before qualifying for general practice.

This was in fact to prepare me culturally and mentally to be a good and articulate Canadian.

When I pointed out that I was born in England of English parents and had attended six years of Manchester Grammar School (which then as now produced a high number of 0xbridge entrants), and that I had served two wartime years in the RAF, some time of that actually in Canada, spoke English fluently and could hold a knife and fork correctly, the two years pre-dental requirement was reduced to one.

The world was a different place then.

I stayed here, and finally retired in 2008.

B. Posner Alderley Edge DOI: 10.1038/sj.bdj.2011.919

\section{NHS AMAZEMENT}

Sir, I am amazed at the state of NHS dentistry in England. I am a UK graduate and worked faithfully in the NHS for 32 years before emigrating to New Zealand for a more outdoor lifestyle. I now have a grandson in the UK and decided to return for a few months each year to see more of him. I need an income to be able to achieve this, and thought I would easily get a locum job over here.

Imagine my dismay at finding it impossible due to the huge increase in bureaucracy. I need a performer number from the PCT, but cannot get one of these because I have not worked under the new contract. My only way around it is to work under vocational training for a year (not much good for a three month locum!)

I have seen several new contracts come and go, and would probably be able to work the new one out in all its little details in about a week. I have trained new dentists myself and feel I know almost all there is to know about NHS dentistry and running a practice within its confines.

My CPD total is three times as high as it needs to be, as I always keep abreast of all new developments in dentistry. Without meaning to sound racist, my patients understand my English really well, and would welcome my doing a locum as a break from all the foreign accents in their practice.

What has become of the NHS? Thank goodness New Zealand still operates as a sensible, fair-minded piece of old England.

H. R. Read

DOI: 10.1038/sj.bdj.2011.920

\section{THERAPIST OMISSION}

Sir, I note once again the BDA seems to have forgotten that dental therapists exist. We have now been left off your information network form (BDJ 211[2]). I would like to think that many people now consider therapists as an important part of the dental team and my sensitive side is starting to feel hurt at this exclusion!

I have mentioned this on several evaluation forms after attending BDA courses. I hope you will consider changing me from 'other' to 'dental therapist' in the near future.

J. Hughes

By email

DOI: 10.1038/sj.bdj.2011.921

\section{VEGETABLE GRANULOMA}

Sir, Ghafoor et al. reported a case of submandibular radiolucency that led to subsequent correspondence in which Barrett questioned the authors' conclusion that the radiolucency was caused by displaced amalgam (Not justified; BDJ 2011; 211: 243).

As indicated by Barrett, implanted amalgam does not cause clinical granulomas, although it causes microscopical granulomas, and a tattoo can be the clinical result. ${ }^{1}$ Vegetable can be implanted following extraction, and a vegetable granuloma can be the clinical result. ${ }^{2}$ However, the poorly defined margin of the radiolucency and extensive resorption of the adjacent teeth, and the similar, poorly defined margin in the subsequent radiograph, are not features of vegetable granuloma, but they are features of malignancy, which indicates the importance in such bizarre cases of clinical and histological investigations that are more extensive than usual.

\section{J. D. Harrison \\ London}

1. Harrison J D, Rowley PS A, Peters P D. Amalgam tattoos: light and electron microscopy and electron-probe micro-analysis. J Pathol 1977; 121: 83-92.

2. Harrison J D, Martin I C. Oral vegetable granuloma: ultrastructural and histological study. J Oral Pathol 1986; 15: 322-326.

DOI: 10.1038/sj.bdj.2011.922

\section{TIME FOR CHANGE?}

Sir, for many years the divide between dentistry and medicine has been evident; however, the integration of combined undergraduate teaching in some universities has gone some way to address this issue.

There still, however, appears to be a lack of basic dental knowledge amongst most new medical graduates, an issue that has become apparent during my time as a Senior House Officer in Oral and Maxillofacial Surgery at a busy regional unit.

A significant proportion of the attendances at hospital ActE departments that present with oral and maxillofacial conditions, could be sufficiently managed by medical staff ie incision and drainage of a dental abscess.

The on-call maxillofacial workload is already stretched, particularly at weekends due to the high number of trauma admissions and general ward work. Therefore simple cases not only place further demand on limited resources but also cause more patient distress through a prolonged assessment, diagnosis and treatment pathway.

Through further emphasis in the undergraduate medical course, it could be possible to create clinicians more confident and competent in the basic management of common oral and maxillofacial conditions.

Perhaps the time for change is here? 